\title{
MODELLING INFRAGRAVITY WAVES AND CURRENTS ACROSS A FRINGING CORAL REEF
}

\author{
Ap Van Dongeren ${ }^{1}$, Ryan Lowe ${ }^{2}$, Andrew Pomeroy ${ }^{1,2,3}$, Duong Minh Trang ${ }^{1,4}$, Dano \\ Roelvink $^{1,3,4}$, Graham Symonds ${ }^{5}$ and Roshanka Ranasinghe $e^{1,3,4}$
}

\begin{abstract}
Low-frequency (infragravity) wave dynamics on a fringing coral reef were investigated using the numerical model XBeach (Roelvink et al, 2009). First, the skill of the one-dimensional model was evaluated based on its predictions of short waves $(0.04-0.2 \mathrm{~Hz})$, infragravity waves $(0.004-0.04 \mathrm{~Hz})$ and water level measurements (tidal elevation and wave setup) obtained during a 2009 field study at Ningaloo Reef in Western Australia. The model calibration was sensitive to friction coefficients for short waves and current / infragravity bed friction, which were assumed independent in this model study. The infragravity waves were found to be generated primarily in the surf zone through the breakpoint generation mechanism rather than through offshore forcing. The infragravity waves were also strongly modulated over the reef by tidal depth variations, primarily due to the variability in frictional dissipation rates when the total water depth over the reef varied. The results revealed that short waves dominated bottom stresses on the forereef and near the reef crest; however, inside the lagoon, infragravity waves become increasingly dominant, accounting up to $50 \%$ of the combined bottom stresses.
\end{abstract}

Keywords: fringing coral reefs; hydrodynamics; wave breaking; infragravity waves; low frequency waves; surfbeat; XBeach

\section{INTRODUCTION}

A large percentage of the world's coastlines contain a broad class of submerged reef structures, including tropical coral reefs. However, little work (as compared to sandy beaches) has addressed the range of nearshore hydrodynamic processes in reef environments. A good understanding of these processes is important because waves and wave-induced currents on reefs ultimately drive sediment transport (e.g., Storlazzi et al., 2004), nutrient dynamics and uptake by benthic reef communities (e.g., Falter et al., 2004), as well as the transport and dispersal of larval fish and other organisms (e.g., Wolanski and Sarsenski, 1997) in these environments. Hydrodynamics are thus important for the morphological development of reef environments and their associated ecological zonation (e.g., Kench and Brander, 2006; Atkinson and Falter, 2003). While reefs protect coasts by dissipating wave energy offshore, severe coastal erosion and flooding may still take place during typhoons and hurricanes (e.g., Ogg and Koslow, 1978, Péquignet et al., 2009). Thus, the impact of environmental changes on a reef and the adjacent coastline (e.g. climate-induced sea level rise), extreme events and/or human interventions can only be accurately predicted with sufficient knowledge of nearshore processes.

Munk and Sargent (1948) first quantified a mean wave set up of several decimeters relative to mean sea level over the reef at Bikini Atoll. Lee and Black (1978) and Hardy and Young (1996) observed the considerable transformation of incident short waves dominated by swell, in terms of wave heights and the spectral redistribution from higher to lower frequencies as the waves broke over the reef. Other field studies have specifically investigated how the transformation of short waves (e.g., swell) on reefs generates mean wave-driven currents across reef systems, primarily due to wave breaking (e.g., Symonds and Black, 2001; Jago et al., 2007; Hench et al., 2008; Lowe et al., 2009a; Taebi et al., 2011). Symonds et al. (1995) first formulated an analytical model based on a linearized set of momentum equations in order to demonstrate the relative importance of set-up and onshore wave-driven flow across an idealized 1D reef system (subsequent 1D analytical models were also formulated by Hearn (1999) and Gourlay and Colleter (2005)). Despite physical differences between

\footnotetext{
${ }^{1}$ Deltares, Delft, The Netherlands

${ }^{2}$ University of Western Australia, Crawley, WA, Australia

${ }^{3}$ Department of Civil Engineering, TU Delft, Delft, Netherlands

${ }^{4}$ Unesco-IHE, Delft, The Netherlands

${ }^{5}$ CSIRO, Floreat, WA, Australia
} 
sandy coast and reef environments, simple 1D (cross-shore) wave transformation models developed for mildly-sloping beaches have been successfully used to investigate short wave transformation over some reefs (Gerritsen, 1980; Lowe et al., 2005 and Sheremet et al., 2011). More complex twodimensional horizontal coupled wave-circulation numerical models have also been developed to predict the spatial distribution of mean wave-driven currents and water levels within reef-lagoon systems (Symonds and Black, 2001; Ranasinghe et al., 2006; Lowe et al., 2009b).

Collectively, these field and modeling reef studies have shown that the physical processes on reefs have similarities to those on sandy coasts (e.g., having submerged bars), albeit with some important differences: the slope of reefs is generally much steeper than the fore slope of sandy shores, the reef bottom topography is much rougher and less homogeneous, and there is typically a larger distance between the breakpoint of the waves and the coastline.

Despite the historical focus on the dynamics of short wave energy (periods of 5-25 seconds) and mean (i.e. averaged over many wave periods) wave-driven flows on reefs, a relatively small number of field studies have identified the importance of lower frequency wave motions (periods of 25 seconds to tens of minutes), termed infragravity (IG) waves, to the overall water motion over coral reef flats and lagoons (e.g., Hardy and Young, 1996; Lugo-Fernandez et al., 1998; Brander et al., 2004). In particular, two recent field studies (Péquignet et al., 2009 and Pomeroy et al., submitted) have shown that the bulk of the water level variability was found to be contained within the IG frequency band, despite the response of the IG waves being somewhat different between systems. Despite the importance of IG wave motions to reefs, process-based numerical models capable of predicting their dynamics have been lacking. Recently Nwogu and Demirbilek (2010) and Sheremet et al. (2011) each applied a 1D phase-resolving wave model to simulate both short wave and IG waves from smooth bed laboratory flume experiments.

The objective of this paper was to investigate and understand the dynamics of IG wave motions across a fringing coral reef. A recently-developed nearshore circulation model (XBeach) (Roelvink et al., 2009) that includes IG wave generation, propagation and decay was used in a case study of Ningaloo Reef, a large fringing reef located on the northwest coast of Western Australia.
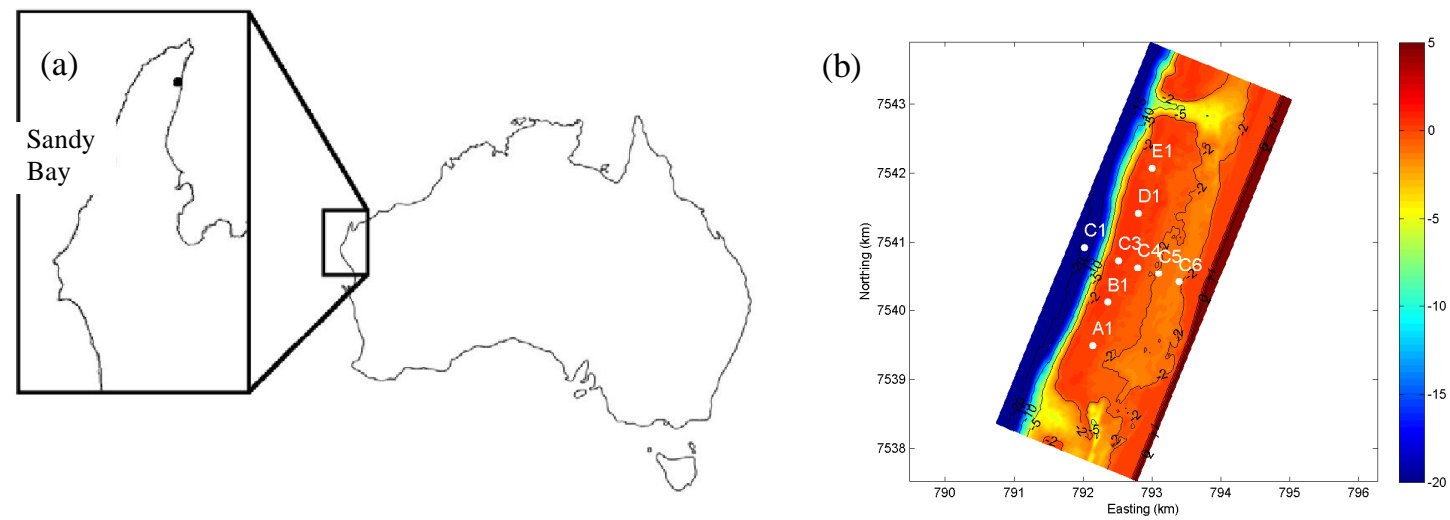

Figure 1. (a) Location of Ningaloo Reef and the study site at Sandy Bay in Western Australia. (b) Plan view of the surveyed bottom contour elevations (relative to Australian Height Datum, equivalent to approximately mean sea level) with the instrument locations superimposed.

\section{FIELD OBSERVATIONS}

This study focuses on the hydrodynamics occurring within an $\sim 7 \mathrm{~km}$ section of Ningaloo Reef at Sandy Bay (Figs 1a and b), which is composed of a shallow reef flat ( 1-2 m depth) that is separated from the shore by a slightly deeper lagoon ( 2-3 $\mathrm{m}$ average depth). The reef is broken to the north and south of the study area by channels, through which water exchange between the lagoon and the ocean occurs (Taebi et al, 2011). This present study employs data from a field experiment conducted in June 2009, which provided the offshore wave forcing and data on the forereef, reef flat and lagoon that was required to drive and validate the numerical models. A detailed description of the study site, the field 
experiment, and results are discussed by Pomeroy et al, (submitted). During the field experiment, a synchronized cross-shore and alongshore array of instruments was deployed (Fig. 1b). The present study focuses on the measurements obtained from the roughly perpendicular cross-shore transect (C1C6) (Fig. 1c). Instrument C1 was deployed on the forereef slope, C3 and C4 were located on the reef flat, while C5 and C6 were located inside the lagoon behind the reef.

The mean water level variability measured on the forereef at $\mathrm{C} 1$ (where wave setup / setdown is negligible) was dominated by the spring-neap variability of the tide (Fig. 2a). Short wave heights (integrated over the band 0.04-0.2 Hz) and IG wave bands (0.004-0.04 Hz) are shown in Figs 2e-f. On the forereef at $\mathrm{C}$, the short waves overwhelmingly dominated over the IG waves (Fig. 2b). In contrast, on the seaward edge of the reef (C3), the short wave heights were substantially reduced and were comparable to the IG wave heights (Fig. 2c). The short and IG wave heights decreased across the reef (C4) and lagoon (C5 and C6) with the short wave heights decaying more rapidly across the reef than the IG wave heights (Figs 2d-f). A general increase in wave heights (short wave and IG) on the reef was observed during the two swell events that occurred around June 15 and June 25. This is also reflected in the variance density spectra. Fig. $2 \mathrm{~g}$ shows the frequency distribution versus time at $\mathrm{C} 1$ where very little energy is contained within the IG frequency band, with the exception of the period 14-19 June, when the incident short wave heights were relatively large. The increasing dominance of the IG waves over the reef (C3) and into the lagoon (C5) is clearly visible in Figs $2 \mathrm{~h}$ and $2 \mathrm{i}$, where most of the incident short waves have dissipated.
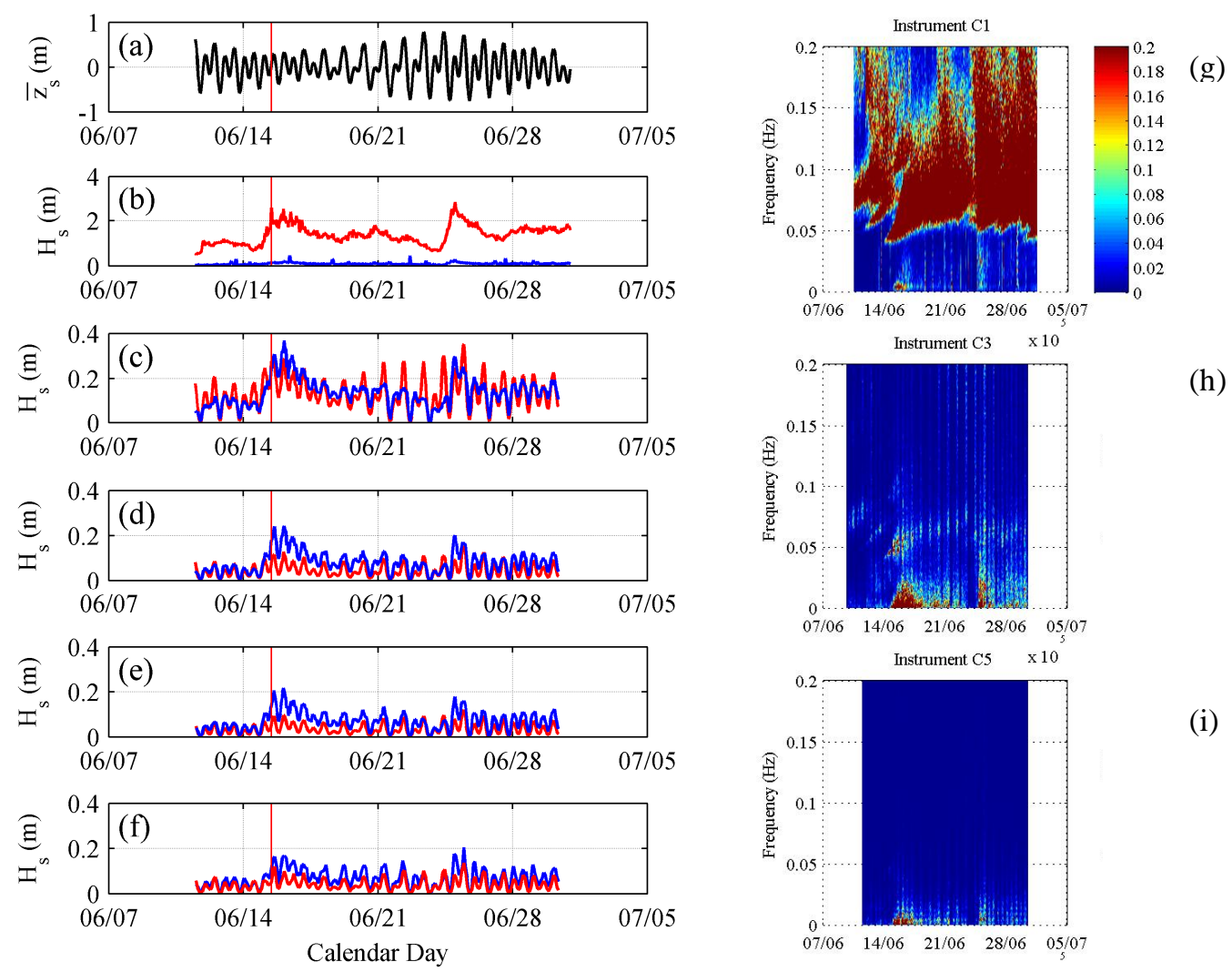

Figure 2 (a) Time series of the mean water level (tide) measured on the forereef at $\mathrm{C} 1$. Root-mean-square wave heights for the infragravity wave band $\mathrm{H}_{\mathrm{rms}, \mathrm{IG}}$ (blue) and short wave band $\mathrm{H}_{\mathrm{rms}, \mathrm{sw}}$ (red) measured across the reef at (b) C1, (c) C3, (d) C4, (e) C5 and (f) C6. The vertical red lines denote the period of the peak swell event simulated on June 15 at 11:00. (g) variance density spectrum at C1, (h) at C2, (i) at C3.

\section{NUMERICAL MODELLING}

\section{Model description}

The numerical model XBeach (see Roelvink et al., 2009 for a complete description of the equations) solves the coupled time-dependent 2DH (horizontal) equations of wave action propagation and dissipation (on the scale of the wave groups), and the $2 \mathrm{DH}$ equations of conservation of mass and 
momentum (for IG and mean surface elevation and currents). The model was forced by varying (spectral) wave and flow boundary conditions. The model includes the dynamics responsible for IG wave generation, propagation and decay. The only relevant change in the version that was applied here was the inclusion of an additional term in the wave action balance to account for bottom friction dissipation $\mathrm{D}_{\mathrm{f}}$ of the short waves. Such bottom friction has been shown to play an important or even dominant role in reef environments (e.g., Lowe et al., 2005). The wave action equation for the short waves was thus modeled as:

$$
\frac{\partial A}{\partial t}+\frac{\partial c_{x} A}{\partial x}+\frac{\partial c_{y} A}{\partial y}+\frac{\partial c_{\theta} A}{\partial \theta}=-\frac{D_{b}}{\sigma}-\frac{D_{f}}{\sigma}
$$

where $\mathrm{A}$ is the wave action, $\mathrm{c}_{\mathrm{x}}, \mathrm{c}_{\mathrm{y}}$ and $\mathrm{c}_{\theta}$ are the propagation speeds in $2 \mathrm{D}$ horizontal and directional space (refraction), $D_{b}$ is the rate of dissipation due to wave breaking and $\sigma$ is the representative radian wave frequency. The rate of bottom friction dissipation $\mathrm{D}_{\mathrm{f}}$ was modeled as (e.g., Jonsson, 1966):

$$
D_{f}=\frac{2}{3} \rho \pi f_{w}\left(\frac{\pi H}{T_{m 01} \sinh k h}\right)^{3}
$$

Here $f_{w}$ is the short-wave friction coefficient, $T_{m 01}$ is the mean period defined by the first- and zeroth moments of the wave spectrum, and $\mathrm{h}$ is the water depth. In Eq. (2), H is the instantaneous root-meansquared wave height defined as twice the value of the amplitude of the wave group envelope at a given time, which can be calculated from the wave action A (see Roelvink et al., 2009). The momentum equations used to compute the mean currents, as well as time-varying IG wave orbital velocities and surface elevations (see Roelvink et al., 2009 for the full equations), contain a friction term following Ruessink et al., 2001, and are thus considered separately from each other. Studies conducted on reefs (e.g. Lowe et al., 2007) indicate that $f_{w}$ should be an order of magnitude (or more) larger than $c_{f}$ due to the dependency of wave frictional dissipation rates on the frequency of the motion.

\section{Model calibration}

Initially, the model was run in $1 \mathrm{D}$ to identify the sensitivity of the model to the friction parameters $f_{w}$ and $c_{f}$. A single wave condition $\left(H_{s}=\sim 2.5 \mathrm{~m}, T_{p}=\sim 19 \mathrm{~s}\right)$, corresponding to a peak swell event that occurred on June 15 around 11:00 (Fig. 1), was prescribed at the offshore boundary. The $1 \mathrm{D}$ model was run for three different values of the short-wave friction coefficient $\mathrm{f}_{\mathrm{w}}(0,0.3,0.6)$, while the current friction coefficient was held constant at $c_{f}=0.1$ for all three cases. The absence of short-wave friction $\left(f_{w}=0\right)$ resulted in an over prediction of the short wave heights across the reef (Fig. 3a). As $\mathrm{f}_{\mathrm{w}}$ was increased, $\mathrm{H}_{\mathrm{rms}, \mathrm{sw}}$ was more accurately reproduced across the reef, with very good agreement for $f_{w}=0.6$ (Fig. 3a). The IG wave height transformation (Fig. 3c) and the mean water level prediction (Fig. 3e) also improved somewhat as $f_{w}$ was increased; although both remained consistently over predicted.

A separate set of three simulations was then conducted, this time using a constant short wave friction coefficient $\left(f_{w}=0.6\right)$ but for three values of the current friction coefficient $c_{f}(0.05,0.1,0.3)$. For the higher friction coefficient value of $c_{f}=0.3$, differences in the short wave heights $\mathrm{H}_{\mathrm{rms}, \mathrm{sw}}$ were minimal (Fig. 3b, not visible in the plot). However, the IG wave heights $\mathrm{H}_{\mathrm{rms}, \mathrm{IG}}$ improved, but these performance gains were at the expense of an increasing and significant over prediction in the mean water levels over the reef (Fig. 3d,f). The lower value of $c_{\mathrm{f}}=0.05$ produced the opposite effect, leading to a lower mean water level (which was more in agreement with the data); however, IG wave heights were significantly overpredicted (Fig. 3d). The optimal combination of friction coefficients from these sensitivity tests was thus $\mathrm{f}_{\mathrm{w}}=0.6$ and $\mathrm{c}_{\mathrm{f}}=0.1$. 

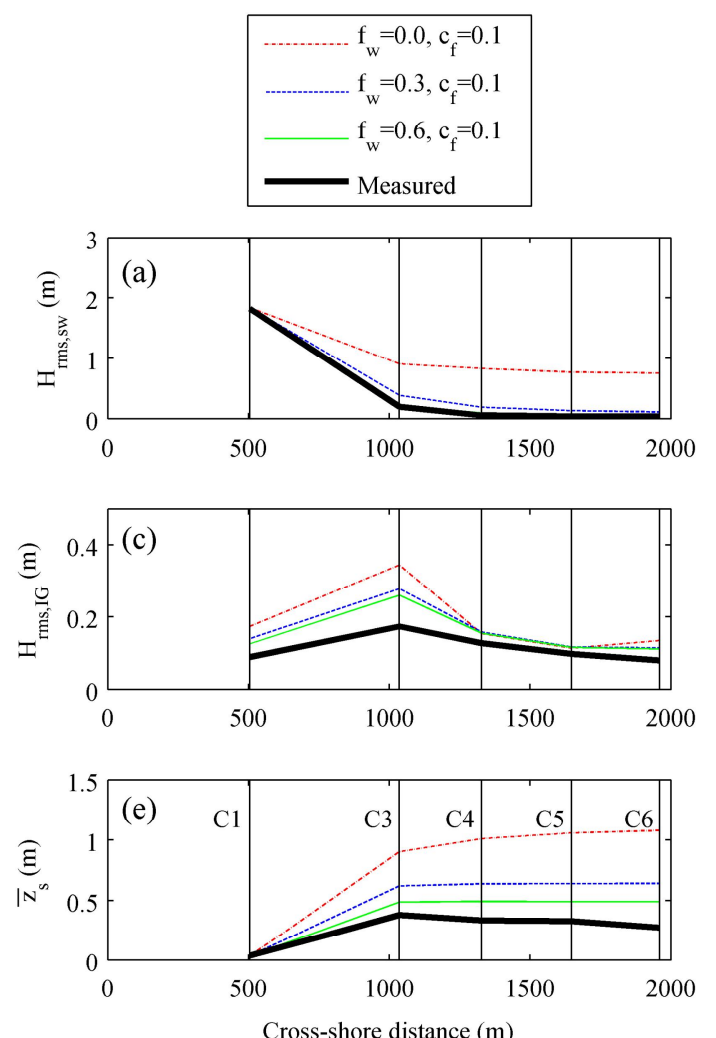
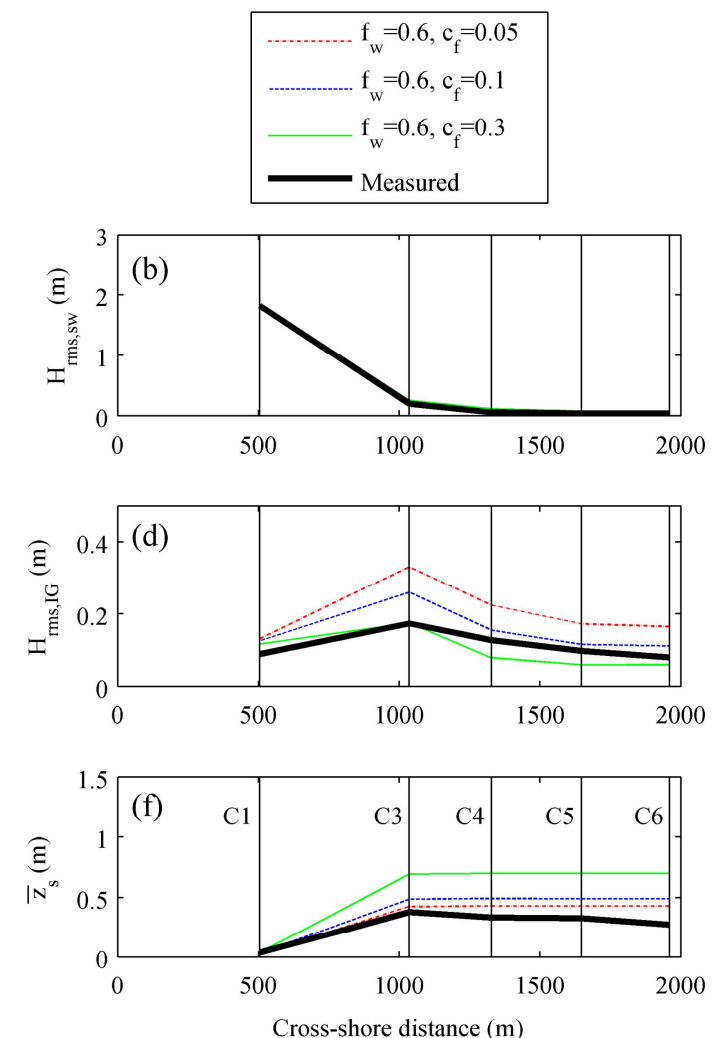

Figure 3. 1D model simulations of the peak swell event (June 15 at 11:00). The left panels show the response to varying $f_{w}$, while the right panels show the response of varying $c_{f .}(a, b)$ Short wave height $H_{r m s, s w}$ transformation as a function of cross-shore distance, (c,d) IG wave height $H_{r m s, I G}$, $(e, f)$ mean water level relative to the offshore value (i.e., representing wave setup).

$\mathrm{H}_{\text {s.sw }}(\mathrm{m})$
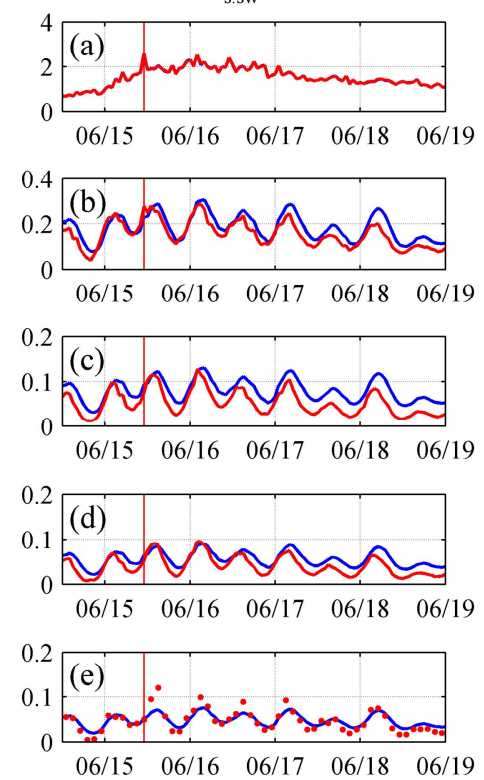

$\mathrm{H}_{\text {s.IG }}(\mathrm{m})$
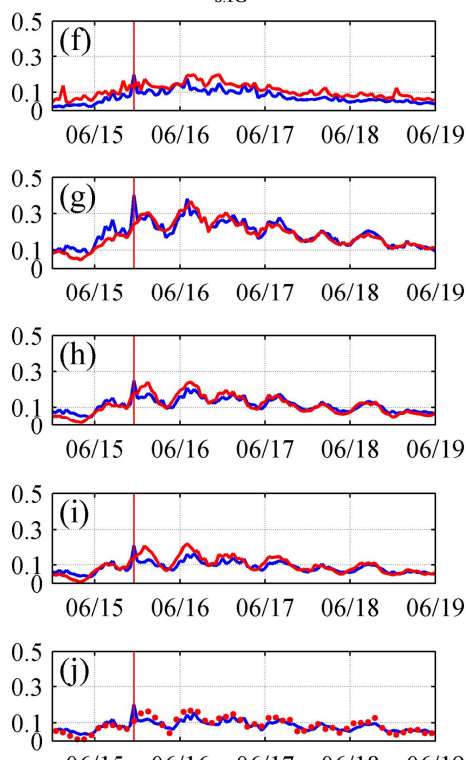

$\begin{array}{lllll}06 / 15 & 06 / 16 & 06 / 17 & 06 / 18 & 06 / 19\end{array}$ $\overline{\mathrm{z}}_{\mathrm{s}}(\mathrm{m})$
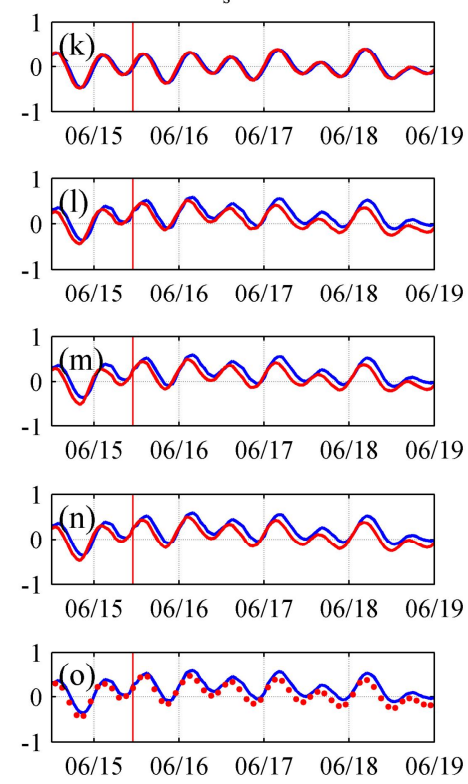

Figure 4 Comparison between the 1D model results (blue) and measured data (red) for the duration of the $\sim 5$ day swell event. $(a, f, k)$ are for instrument $\mathrm{C} 1,(b, g . l) C 3,(c, h, m) C 4,(d, i, n) C 5$ and $(e, j, o)$ C6. The peak of the storm is indicated by the red vertical line. Note the large reduction in vertical scale between $\mathrm{C} 1$ and the reef sites C3-C6. 


\section{Model validation}

This set of bottom friction coefficient values was subsequently used to simulate the entire swell event from June 14 12:00 hours to June 19 00:00 hours (109 hours in total) when wave conditions varied significantly. This allowed for an evaluation of the model performance under a wide range of incident short wave conditions. The swell event duration was represented in the model as a sequence of hourly sea states, from which the wave forcing was generated at the offshore boundary. Good agreement was generally observed throughout the simulation and at all sites (Fig. 4). The model reproduced the spatial variability in wave heights across the reef, as well as temporal changes in the response to the varying offshore wave conditions and tidal variations. The short wave height predictions matched the data reasonably well (Fig. 4a-e), except for a small positive bias of a few centimeters. The IG wave heights were slightly under predicted (negative bias) at $\mathrm{C} 1$, but were generally in very good agreement for sites on the reef (Fig. 4f-j). The time series of the predicted mean water levels followed the observed time series quite closely; however, a small phase lag was observed for sites on the reef, but not offshore (Fig. 4k-o). Both the field observations and model results displayed a strong positive correlation between changes in the IG wave heights over the reef and the mean water depth (tidal) variations. This variation is not due to significant differences over the tidal cycle in the rate of IG generation in the surf zone, but primarily due to the tidal modulation in the rates of frictional dissipation associated with the changing depth of the water column (Van Dongeren et al., submitted).

\section{Model analysis: IG wave generation mechanisms on coral reefs}

IG wave generation has been studied thoroughly on sandy beaches from which two mechanisms are known: (1) IG waves in the form of (coupled) forced long waves that are generated by nonlinear interactions between incident (primary) sea/swell waves ((Longuet-Higgins and Stewart, 1964). These waves travel from deep water and, due to the continuous forcing of these waves by the shoaling primary short waves, are amplified over the sloping seabed in the nearshore zone up to the zone of initial breaking (e.g., List, 1992; Masselink, 1995) and possibly within the surf zone (Foda and Mei, 1981; Schäffer and Svendsen, 1988). These waves are often referred to as shoaling bound long waves (Battjes et al., 2004). Alternatively, (2) free IG waves may be generated within the surf zone of a sloping beach by the time-varying oscillation (excursion) of the short wave breakpoint (Symonds et al., 1982). These IG waves are often referred to as 'breakpoint generated waves'. The latter mechanism is thought to dominate as the relative slope at the breakpoint increases, which implies that a transition exists between these two generation regimes based on the slope (Battjes et al., 2004; see also Baldock, 2012 for a recent review).
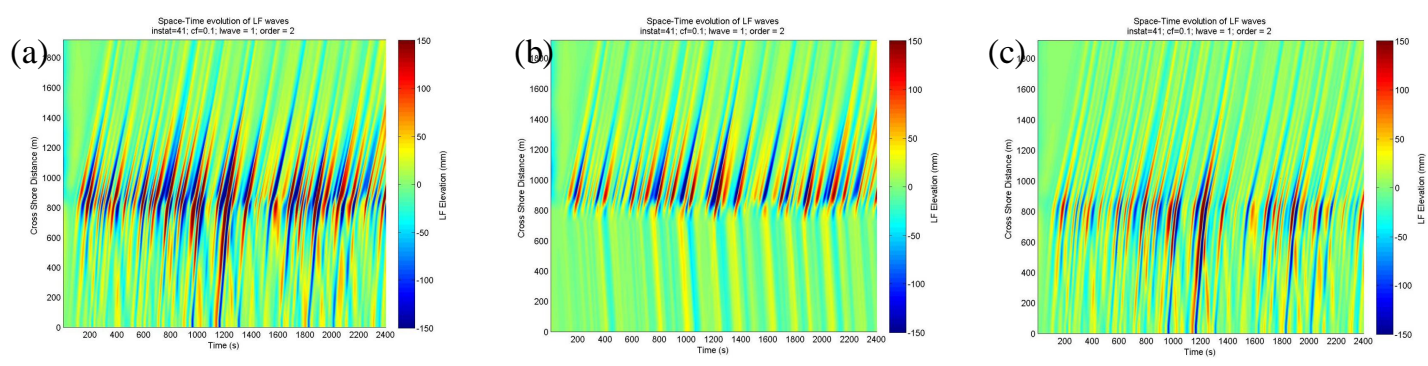

Figure 5 Time stacks of IG surface elevations (cross-shore distance vs. time): (a) full model solution with both bound and surf zone generated waves included in the model, (b) surf zone generated wave contribution (no bound wave generation) and (c) the bound wave contribution (no surf zone generation).

For the rather steep fore reef slopes of coral reefs, we investigated which mechanism is dominant by isolating generation processes. First we ran a numerical experiment with irregular wave forcing applied throughout the whole domain using the conditions observed during a swell peak (16 June 05:00) and with bottom friction turned on $\left(f_{c}=0.06\right)$ and applied uniformly throughout the model domain. Inspection of the time series results with full forcing (Fig. 5a) reveals a complex pattern of IG waves in the offshore region $(x<900 \mathrm{~m})$, which is due to the interaction between the incident bound waves and the seaward propagating surf zone (breakpoint) generated IG waves. When the bound wave forcing is turned off in the offshore region (Fig. 5b), only seaward directed waves are observed offshore of the surf zone, along with shoreward propagating IG waves out of the surf zone, yet the 
pattern on the reef is effectively the same as the full forcing case, i.e. the inclusion of the incident bound waves do not make an important contribution to the IG wave heights observed on the reef. Likewise for the case with the generation of the surf zone (breakpoint) forcing turned off (Fig. 5c), the IG wave patterns on the reef are substantially different on the reef, relative to the full forcing case.

\section{Model application: relative contribution of shear stresses}

The results from this study emphasize the importance of IG waves to coral reef systems, which compared to other hydrodynamic processes (e.g., short wave transformation and mean wave-driven currents), have frequently been neglected. The spatial importance of IG waves versus other processes (i.e., short waves and mean currents) is illustrated by computing the percentage of the total bed stress associated with each process, shown in Fig. 6 during the peak swell event in a 2D application. The components of the bed shear stress are computed for the mean currents, IG waves and swell waves, diagnostically as

$$
\begin{aligned}
& \tau_{c}=\rho c_{f}\left(\bar{U}_{E}^{2}+\bar{V}_{E}^{2}\right) \\
& \tau_{I G}=\rho c_{f}\left(\overline{U_{E}^{2}}-\bar{U}_{E}^{2}+\overline{V_{E}^{2}}-\bar{V}_{E}^{2}\right) \\
& \tau_{s w}=\frac{1}{2} \rho f_{w} u_{r m s, s w}^{2}
\end{aligned}
$$

where for the infragravity-wave component only the time-varying components of the Eulerian velocities $\left(\mathrm{U}_{\mathrm{E}}, \mathrm{V}_{\mathrm{E}}\right)$ are taken into account.
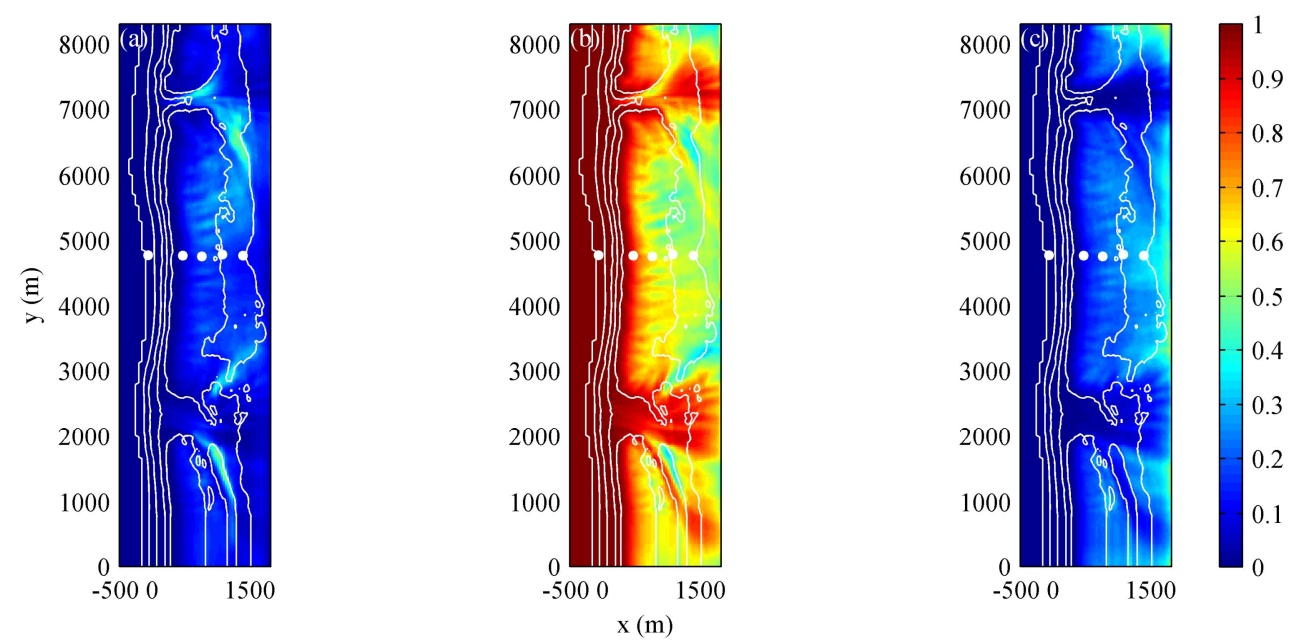

Figure 6 The fraction (denoted by the colorbar) of total bottom stress induced by (left)) the mean currents (middle) short waves (right) and IG waves, averaged over the duration of the 2DH model during the peak swell event. The white dots indicate the locations of the instruments used in the field experiment.

The results show that mean currents generally account for less than $20 \%$ of the bottom shear stresses that occur over the reef and throughout most of the lagoon (Fig. 6a). On the forereef and near the reef crest (offshore of the surf zone), short waves account for almost $100 \%$ of the shear stresses observed (Fig. 6b). However, the influence of the short waves dramatically decreases across the reef flat and within the lagoon, typically accounting for $<40 \%$ of the shear stresses in the lagoon. Notably, the contribution of IG waves to the total shear stresses gradually increases across the reef towards the lagoon and ultimately becomes the dominant contribution (generally accounting for up to $50 \%$ of the shear stress in the lagoon) (Fig. 6c). The significant contributions played by the IG waves thus have important implications for the modeling of a number of hydrodynamically-coupled processes that occur in reef systems; for example, rates of sediment transport in coral reef lagoons and the masstransfer limited nutrient uptake by coral reef communities. It is therefore critical that these IG wave 
dynamics are included in future hydrodynamic, morphological and ecological modeling studies of reef systems.

\section{CONCLUSIONS}

This study demonstrates that the nearshore circulation model XBeach with an unsteady wave driver, initially developed for sandy coast applications, can be used with good skill to predict all of the key hydrodynamic processes across fringing reef systems (including the important IG wave dynamics). The only modification to the model equations was the addition of a bottom friction dissipation term in the short wave energy balance, and the calibration of two bed friction coefficients (one for short waves and one for (un)steady currents) to higher values than commonly applied to sandy coast environments. The parameter associated with short wave dissipation $\left(f_{w}\right)$ was an order of magnitude higher than the parameter $\mathrm{c}_{\mathrm{f}}$ associated with unsteady currents (which includes IG waves), consistent with the frequency dependent response of the bottom dissipation rates (Lowe et al., 2007). Once calibrated, the model performed well for the duration of a five day swell event, capturing the variation of the infragravity waves, swell waves and mean water level. An analysis revealed that the infragravity waves are primarily generated by the breakpoint mechanism, rather than by shoaling bound waves. Furthermore, IG wave energy accounted for a significant proportion of the bed shear stresses observed in the lagoon, whereas the short waves dominated on the forereef and reef crest. These findings indicate that the dynamics of IG waves are important across fringing reefs and their lagoons, and hence are likely to have a significant impact on a wide range of reef processes, both physical and biological, that operate within these systems.

\section{ACKNOWLEDGEMENTS}

This research was sponsored by Deltares Strategic Research 1202362 and UNESCO-IHE DUPC MSc publication fund. RJL acknowledges funding provided by an Australian Research Council Discovery grant (DP0770094) and an Australian Research Council Future Fellowship (FT110100201), as well as support from a CSIRO Flagship Collaboration Fund grant.

\section{REFERENCES}

Atkinson, M. J., and J. L. Falter (2003), Coral Reefs, in Biogeochemistry of Marine Systems, edited by K. P. Black and G. B. Shimmield, pp. 40-64, CRC Press, Boca Raton, Florida.

Baldock, T.E. (2012), Dissipation of incident forced long waves in the surf zone - Implications for the concept of "bound" wave release at short wave breaking, Coastal Engineering, 60, 276-285.

Battjes, J. A., and J. P. F. M. Janssen (1978), "Energy loss and set-up due to breaking of random waves", Proc. 16th Int. Conf. Coastal Eng., ASCE, 569-587.

Brander, R. W., P. S. Kench, and D. Hart (2004), Spatial and temporal variations in wave characteristics across a reef platform, Warraber Island, Torres Strait, Australia, Mar. Geol., 207, $169-184$.

Falter, J. L., M. J. Atkinson, et al. (2004). "Mass transfer limitation of nutrient uptake by a wavedominated reef flat community." Limnology and Oceanography 49: 1820-1831.

Foda, M. A., and C. C. Mei (1981), Nonlinear excitation of long-trapped waves by a group of short swells, J. Fluid Mech., 111, 319- 345.

Gerritsen, F. (1980). "Wave attenuation and wave set-up on a coastal reef." Proc. 17th Int.Conf. Coastal Eng., ASCE, 444-461

Gourlay, M. R. and G. Colleter (2005). Wave-generated flow on coral reefs--an analysis for twodimensional horizontal reef-tops with steep faces. Coastal Engineering, 52(4), pp 353-387.

Hardy, T. A., and I. R. Young (1996), Field study of wave attenuation on an offshore coral reef, Journal of Geophysical Research-Oceans, 101(C6), 14311-14326.

Hearn, C.J. (2009). Wave-breaking hydrodynamics within coral reef systems and the effect of changing relative sea level. J. Geophys. Res., 104(C12), 30,007-30,019, doi:10.1029/1999JC900262

Hench, J. L., J. J. Leichter, and S. G. Monismith (2008). Episodic circulation and exchange in a wave-driven coral reef and lagoon system. Limnology \& Oceanography, 53 (6): 2681-2694.

Jago, O. K., P. S. Kench, and R. W. Brander (2007), Field observations of wave-driven water-level gradients across a coral reef flat, Journal of Geophysical Research-Oceans, 112(C6). 
Jonsson, I. G. (1966), Wave boundary layers and friction factors, Proc. Tenth Conference on Coastal Engineering, ASCE, Tokyo, Japan.

Kench, P. S., and R. W. Brander (2006), Wave processes on coral reef flats: Implications for reef geomorphology using Australian case studies, 1072 J. Coastal Res., 22, 209-223, doi:10.2112/05A-0016.1.

Lee, T. T., and Black, K. P. (1978). "The energy spectra of surf waves on a coral reef." Proc.16th Int. Conf. Coastal Eng., ASCE, 588-608.

List, J. (1992), A model for the generation of two-dimensional surf beat, J. Geophys. Res., 97(C4), 5623-5635.

Longuet-Higgins, M. S., and Stewart, R. W. (1964). "Radiation stress in water waves: A physical discussion with applications. Deep Sea Research 11, 529-562

Lowe, R. J., J. L. Falter, M. D. Bandet, G. Pawlak, M. J. Atkinson, S. G. Monismith, and J. R. Koseff (2005), Spectral wave dissipation over a barrier reef, J. Geophys. Res., 110, C04001, doi:10.1029/2004JC002711.

Lowe, R. J., J. L. Falter, J. R. Koseff, S. G. Monismith, and M. J. Atkinson (2007), Spectral wave flow attenuation within submerged canopies: Implications for wave energy dissipation, $J$. Geophys. Res., 112, C05018, doi:10.1029/2006JC003605.

Lowe, R. J., J. L. Falter, S. G. Monismith, and M. J. Atkinson (2009a), Wave-Driven Circulation of a Coastal Reef-Lagoon System, Journal of Physical Oceanography, 39(4), 873-893.

Lowe, R. J., J. L. Falter, S. G. Monismith, and M. J. Atkinson (2009b), A numerical study of circulation in a coastal reef lagoon system, J. Geophys. Res., 114, C06022, doi:10.1029/2008JC005081.

Lugo-Fernandez, A., H. H. Roberts, W. J. Wiseman, and B. L. Carter (1998), Water level and currents of tidal and infragravity periods at Tague Reef, St. Croix (USVI), Coral Reefs, 17(4), 343-349.

Masselink, G. (1995), Group bound long waves as a source of infragravity energy in the surf zone, Continental Shelf Research, 15(13), 1525-1547, ISSN 0278-4343, 10.1016/0278-4343(95)000372.

Munk, W. H., and Sargent, M. C. (1948). "Adjustment of Bikini Atoll to ocean waves." Trans. American Geophysical Union, 29, 855-860.

Nwogu, O. and Demirbilek, Z. (2010). Infragravity wave motions and runup over shallow fringing reefs, ASCE Journal of Waterway, Port, Coastal, and Ocean Engineering (http://dx.doi.org/10.1061/(ASCE)WW.1943-5460.0000050)

Ogg, J. G., and Koslow, J. A. (1978). "The impact of typhoon Pamela, 1976, on Guam's coral reefs and beaches." Pacific Science, 32, 105-118.

Péquignet, A. C. N., J. M. Becker, M. A. Merrifield, and J. Aucan (2009), Forcing of resonant modes on a fringing reef during tropical storm Man-Yi, Geophys. Res. Lett., 36, L03607, doi:10.1029/2008GL036259.

Pomeroy, A.P.M., R. J. Lowe, G. Symonds and A.R. Van Dongeren (submitted). Dynamics of infragravity waves transformation over a fringing reef. Submitted to J. Geoph. Research.

Ranasinghe, R., Turner, I.L., Symonds, G. (2006). Shoreline response to multi-functional artificial surfing reefs: A numerical and physical modelling study Coastal Engineering, 53 (7), pp. 589611.

Roelvink, J.A., A. Reniers, A. Van Dongeren, J. Van Thiel de Vries, R. McCall, J. Lescinski. (2009). Modeling storm impacts on beaches, dunes and barrier islands. Coastal Engineering, doi: DOI: 10.1016/j.coastaleng.2009.08.006.

Ruessink, B. G., M. G. Kleinhans, and P. G. L. van den Beukel (1998), Observations of swash under highly dissipative conditions, J. Geophys. Res., 103, 3111- 3118.

Ruessink, B.G., Miles, J.R., Feddersen, F., Guza, R.T., Elgar, S. (2001). Modeling the alongshore current on barred beaches. J. Geophys. Res. 106, 22451-22463.

Schäffer, H. A., and I. A. Svendsen (1988), Surf beat generation on a mild slope, in Coastal Engineering, 1988, pp. 1058- 1072, Am. Soc. of Civ.Eng., Reston, Va.

Sheremet, A. J.M. Kaihatu, S.-F. Su, E.R. Smith, J.M. Smith (2011). Modeling of nonlinear wave propagation over fringing reefs, Coastal Engineering, Volume 58, Issue 12, December 2011, Pages 1125-1137, ISSN 0378-3839, DOI: 10.1016/j.coastaleng.2011.06.007.

Storlazzi, C. D., A. S. Ogston, et al. (2004). "Wave- and tidally-driven flow and sediment flux across a fringing coral reef: Southern Molokai, Hawaii." Continental Shelf Research 24(12): 1397-1419. 
Symonds, G. and Black, K.P. (2001). Predicting Wave-driven Currents on Surfing Reefs. Journal of Coastal Research Special Surfing Issue 29, 102-114.

Symonds, G., D.A. Huntley and A.J. Bowen (1982). Two dimensional surf-beat: Long wave generation by a time-varying break point. Journal of Geophysical Research, 87, C1, pp. 492-498.

Symonds, G., Black, K. P., andYoung, I. R. (1995). "Wave-driven flow over shallow reefs." $J$. Geophys. Res 100, 2,639-2,648.

Taebi, S., Lowe R.J., Pattiaratchi, C.B., Ivey, G.N., Symonds, G., and Brinkman R. (2011) "Nearshore circulation in a tropical fringing reef system," Journal of Geophysical Research Oceans, 116, C02016, doi: 10.1029/2010JC006439.

Van Dongeren, A.R., R. Lowe, A. Pomeroy, M.T. Duong, J.A. Roelvink, G. Symonds and R. Ranasinghe (2012). Numerical modeling of low-frequency wave dynamics over a fringing coral reef. Submitted to Coastal Engineering.

Wolanski, E. and Sarsenski, J. (1997). Larvae dispersion in coral reefs and mangroves. American Scientist, 85(3), 236-243 